\title{
Assessment of the Level of Interferon-Gamma in the Pathogenesis of Psoriasis
}

\section{Gharib $\mathrm{AF}^{1,2 *}$, Althobaity $\mathrm{AS}^{2}$, ALnemari $\mathrm{SH}^{2}$, Alharthy $\mathrm{RS}^{2}$, Aljohany RS ${ }^{2}$, Alsufyani $\mathbf{R M}^{2}$, Hagag $\mathrm{HM}^{2,3}$, Khalifa $\mathbf{M}^{4}$, Khamis} $\mathrm{AA}^{4}$ and Ismail KA ${ }^{2,5}$

${ }^{1}$ Department of Medical Biochemistry, Faculty of Medicine, Zagazig University, Egypt

${ }^{2}$ Department of Laboratory College of Applied Medical Science, Taif University, KSA

${ }^{3}$ Department of Pathology, Al Azhar University, Egypt

${ }^{4}$ Consultant Dermatologist, Egypt

${ }^{5}$ Department of Medical Parasitology, Ain Shams Faculty of Medicine, Egypt

*Corresponding author: Amal Fathi Gharib, Department of Medical Biochemistry, Shobra street, EL Azizia, Taif University, KSA; Tel no: 00966580278110; Email: dr.amal.f.gharib@gmail.com

\section{Abstract}

Background: Psoriasis is a chronic autoimmune condition characterized by infiltration of keratinocytes by inflammatory cells that cause scaling on the skin surface. Psoriasis is considered now as T cell-mediated disease. INF- $\gamma$ is considered a key cytokine in the pathogenesis of psoriasis.

Objectives: To evaluate the level of IFN gamma in order to recognize its role in the pathogenesis of psoriasis and its relation to the severity of the disease.

Materials and Methods: We investigated the level of serum IFN- $\gamma$ in 40 patients with psoriasis and in 25 healthy controls by ELISA Kit. We used the PASI score to assess the severity of psoriasis.

Results: The serum levels of IFN- $\gamma$ were elevated in all patients with psoriasis but not in all healthy controls. Also, the serum levels of IFN- $\gamma$ were correlated with the severity of disease in psoriatic patients.

Conclusion: The level of IFN- $\gamma$ can be used as a useful estimate of the severity of the disease and may be used in daily practice as prognostic follow-up marker.

Keyword: Psoriasis; IFN- $\gamma$; PASI score

Abbreviations: KCs: Keratinocytes; DCs: Dendritic Cells; IFN- $\gamma$ : Interferon-Gamma; PASI: Psoriasis Area and
Severity Index; SPSS: Statistical Package for Social Science; SD: Standard Deviation; ELISA: Enzyme-Linked Immunosorbent Assay. 


\section{Annals of Immunology \& Immunotherapy}

\section{Introduction}

Psoriasis is a persistent chronic, relapsing, inflammatory, and hyper proliferative skin disorder affecting $\sim 2-3 \%$ of the population. Many environmental factors have been shown to play a role in psoriasis pathogenesis. External triggers such as physical trauma, infection, stress, drug, and alcohol can generate an initial episode of psoriasis in those individuals who already have a genetic predisposition [1]. Psoriasis is considered now as $\mathrm{T}$ cell-mediated disease. The interaction between hyper proliferative keratinocytes (KCs), inflammatory dendritic cells (DCs), neutrophils, mast cell and T cell, induced to development of psoriatic lesions [2-6]. INF- $\gamma$ is considered the key cytokine in previous interaction. The reaction of these components to injury allows an effective cutaneous response to restore homeostasis [7,8]. It's including the innate and the adaptive immune compartment, interfering with skin tissue cells. Primarily, the pathogenic events were thought to depend on the upregulation of interferon (IFN- $\gamma$ ) and interleukin (IL-12) with both group of IFN- $\gamma$ producing T cells (Th1 and Tc1 cells, prospectively) as have important roles [7-9].

Interferon-gamma (IFN- $\gamma$ ) is produced by $\mathrm{T}$ and $\mathrm{NK}$ cells, and in smaller amounts by dendritic cells and macrophages. IFN- $\gamma$ regulates both innate and adaptive immunity by activation of macrophages and multiple cytokines, enhance antigen presentation and broadspectrum pathogen defense $[10,11]$.

Interferon-gamma (IFN- $\gamma$ ) is considered a key cytokine in the pathogenesis of psoriasis; it mediates interactions between inflammatory $\mathrm{T}$ cells and keratinocytes, facilitating T-cell migration to the lesional epidermis where they together motivate the formation of a primary psoriatic plaque. During this step, some $\mathrm{T}$ cells and dendritic cells start to infiltrate the epidermis, releasing pro-inflammatory cytokines, which in turn stimulate keratinocyte proliferation leading to the production of psoriatic lesion [10].

Up till now, there does not yet exist an objective laboratory parameter to measure the severity of psoriasis, in this study, we evaluated the association between serum levels of IFN- $\gamma$, and its correlation with severity of psoriasis in Taif population, KSA.

\section{Subjects and Methods}

\section{Subjects}

This case-control study was conducted in the College of Applied Medical Sciences at Al-Taif University on 40 psoriatic patients and 25 healthy controls, blood samples were collected from King Abdu AL Aziz specialized hospital, Taif, KSA. Psoriasis was diagnosed clinically, based on characteristic plaque-type psoriatic lesions. The psoriasis area and severity index (PASI) was used to assess the psoriasis severity for each patient [12]. A control group consisted of 25 healthy volunteers with no psoriasis or family history of psoriasis. Informed consents were taken from all patients and controls included in the study. Patients with diabetes mellitus, hypothyroidism, hyperlipidemia, hypertension, liver, and kidney diseases were excluded from the study.

\section{Methods}

History taking: Age, sex, duration of the disease and start of treatment.

Blood samples: $5 \mathrm{ml}$ venous blood samples were drawn i $\mathrm{n}$ vacationer tubes under completely sterile conditions fro $\mathrm{m}$ patients and controls in the early morning. The samples were centrifuged and the sera were frozen and stored at -20 ? $\mathrm{C}$ until the time of assay.

IFN- $\gamma$ detection: IFN- $\gamma$ was measured by using enzymelinked Immunosorbent assay (ELISA) kits (Biosciences, USA, and BD Biosciences, USA) according to the manufacturers' instructions. Read absorbance at $450 \mathrm{~nm}$ (reference filter: 630). Read the plate within 30 minutes after adding the Stop Solution. Use curve fitting software to generate the standard curve. Read the concentrations for unknown samples and controls from the standard curve.

Histopathology: Skin biopsies were taken from the lesions of the patients included. Biopsies were immediately fixed for histopathological examination in formalin. Sections have been stained with Haematoxylin and Eosin stain using regular histological laboratory techniques. Histopathological assessment of the biopsies was performed and included eight factors (epithelial hyperplasia, Para keratosis, micro abscesses of Munro and Kogoj, suprapapillary thinning, inflammatory infiltration, widening of rete ridges and capillary proliferation)

Statistical analysis: The statistical package for social science (SPSS) 20.0 for Windows was used to analyze data. Data were presented as mean \pm standard deviation (SD). The statistical significance was accepted as a $P$ value $<0.05$.

Ethical consideration: Ethical approval for this study was obtained from the Ethics Review Committee of the College of Applied Medical Sciences at Al-Taif University. 


\section{Annals of Immunology \& Immunotherapy}

Moreover, all patients included in the study were informed of the study objectives and written signed consent was taken from each one of them.

\section{Results}

This study included 40 patients (23 males, 17 females), with a mean age of $35 \pm 15.5$ (Range: 16-65) years. 25 healthy volunteers (14 male, 11 females) with age and sex-matched have participated in the study. The patients had a mean duration of illness $5 \pm 10.3$ years. Assessment of the psoriasis area and severity index (PASI) revealed average score of $8.5 \pm 8.12$ (range: 1.636.4).

\begin{tabular}{|c|c|c|}
\hline & Patients Number (\%) & Controls Number (\%) \\
\hline Gender & & $14(56)$ \\
\hline Male & $23(57)$ & $11(44)$ \\
\hline Female & $17(43)$ & $33 \pm 14.3$ \\
\hline Age (years) & $35 \pm 15.5$ & $19-63$ \\
\hline Mean \pm SD & $16-65$ & - \\
\hline Range & & - \\
\hline Duration of Disease & $5 \pm 10.3$ years & \\
\hline Mean \pm SD & May-45 & - \\
\hline Range & & - \\
\hline PASI Score & $8.5 \pm 8.12$ & \\
\hline Mean \pm SD & $1.6-36.4$ & \\
\hline Range & & \\
\hline
\end{tabular}

Table 1: Clinical data of the patients.

\begin{tabular}{|c|c|c|c|}
\hline & Patients (n = 40) & Controls (n = 25) & P \\
\hline IFN- $\gamma(\mathrm{ng} / \mathrm{ml})$ & $191.5 \pm 38.2(150-300)$ & $102.3 \pm 23.8(82-221)$ & $<0.001$ \\
\hline
\end{tabular}

Values are mean \pm SD

Table 2: Shows the mean, minimum and maximum values of serum IFN- $\gamma$ in both patients and control group.

There was a significant increase in serum interferon $\gamma$ in psoriatic patients in comparison to control group Table 2.

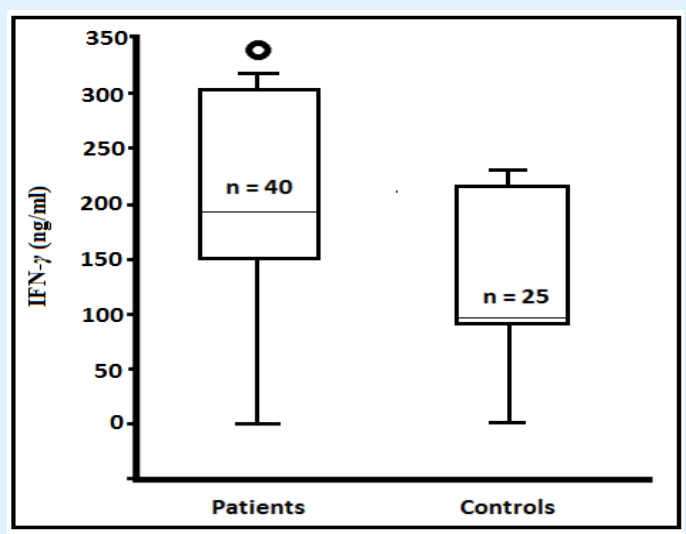

Figure 1: Serum IFN- $\gamma$ levels of psoriatic patients and controls in box plot graphics (0: outliers).

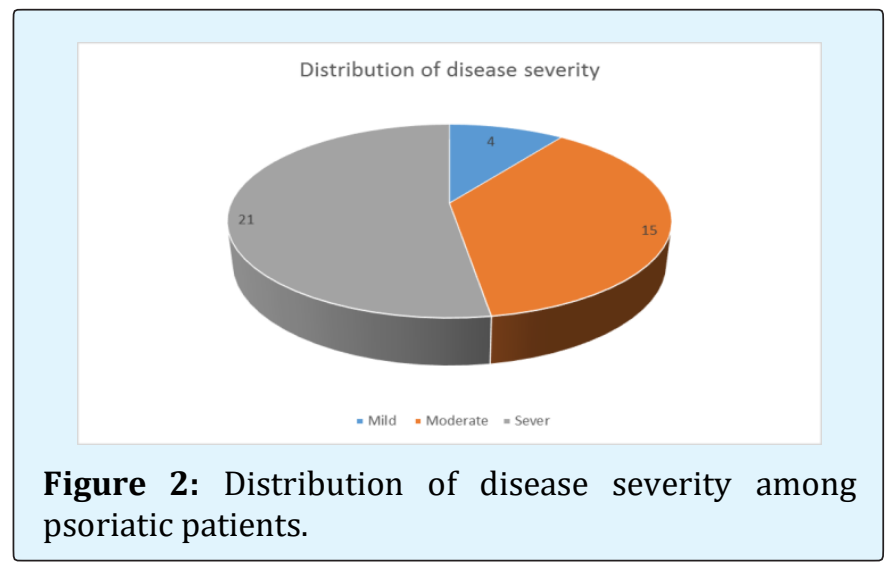

There was a statistical significant correlation between serum levels of IFN- $\gamma$ and severity of the disease, Psoriasis cases with severe PASI score showed highly significant elevated serum IFN- $\gamma$ compared with mild cases $(P 2=0.001)$. Also significant elevation was observed between moderate and severe cases $(P 3=.0001)$. No significant correlation was found between moderate and mild cases of psoriasis $(P 1=0.263)$ (Table 3$)$. 


\section{Annals of Immunology \& Immunotherapy}

\begin{tabular}{|c|c|c|c|c|}
\hline PASI & \multicolumn{2}{|c|}{ IFN- $\gamma$ level } & F- test & P-value \\
\hline & Mean \pm SD & Range & \multirow{4}{*}{7.2} & \\
\hline Mild $(<7) n=4$ & $175.32 \pm 13.01$ & $150.00-197.00$ & & $\mathrm{P} 1=0.263$ \\
\hline Moderate $(7-12) n=15$ & $173.1 \pm 19.4$ & $166.00-207.00$ & & $\mathrm{P} 2=0.001$ \\
\hline Severe $(>12)(n=21)$ & $212.4 \pm 37.32$ & $166.00-301.00$ & & $\mathrm{P} 3=0001$ \\
\hline
\end{tabular}

Table 3: Serum levels of IFN- $\gamma$ and PASI score.

$\mathrm{P}_{1}$, between mild and moderate PASI groups, $\mathrm{P}_{2}$, between mild and severe PASI groups; $\mathrm{P}_{3}$, between moderate and severe PASI groups.
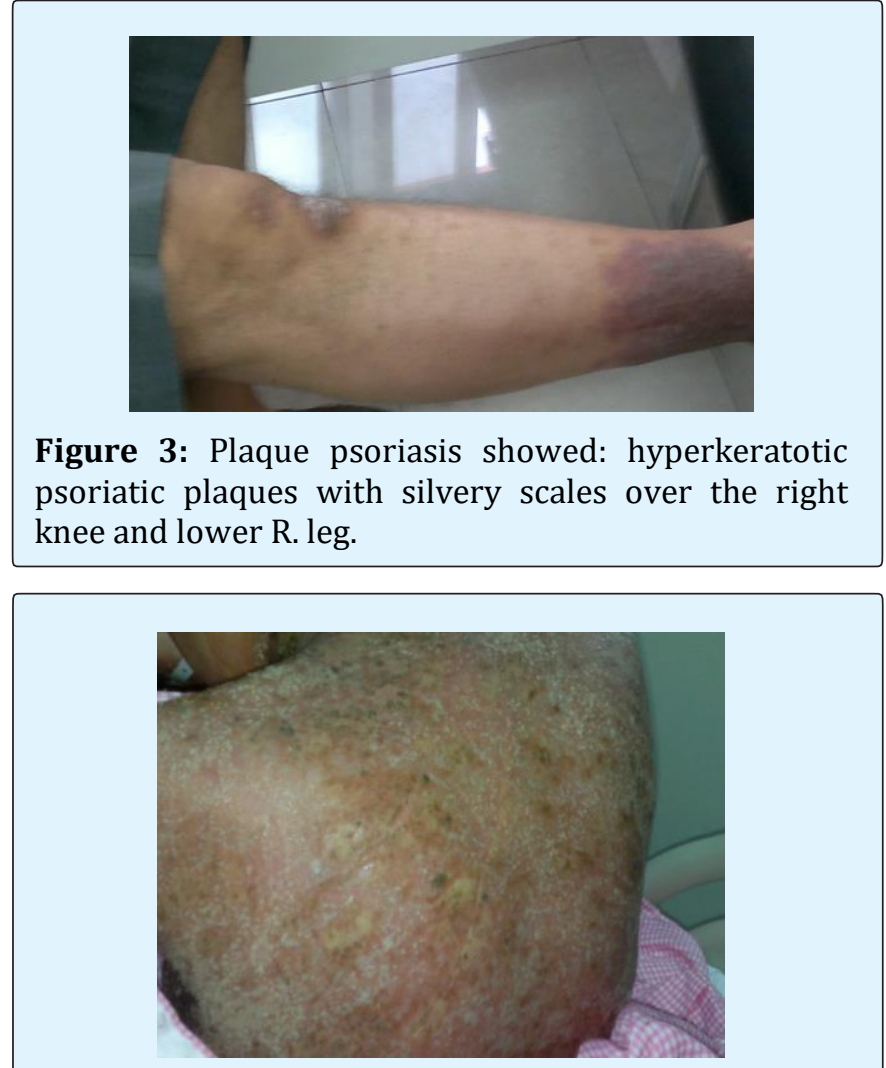

Figure 4: Pustular psoriasis showed: none follicular sterile pustules over the back, some lesions are exfoliated.

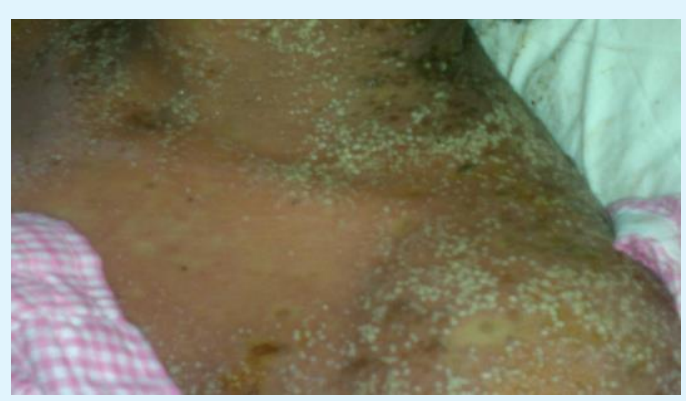

Figure 5: Pustular psoriasis of the same patient in the neck, chest, R. shoulder and R. upper arm.

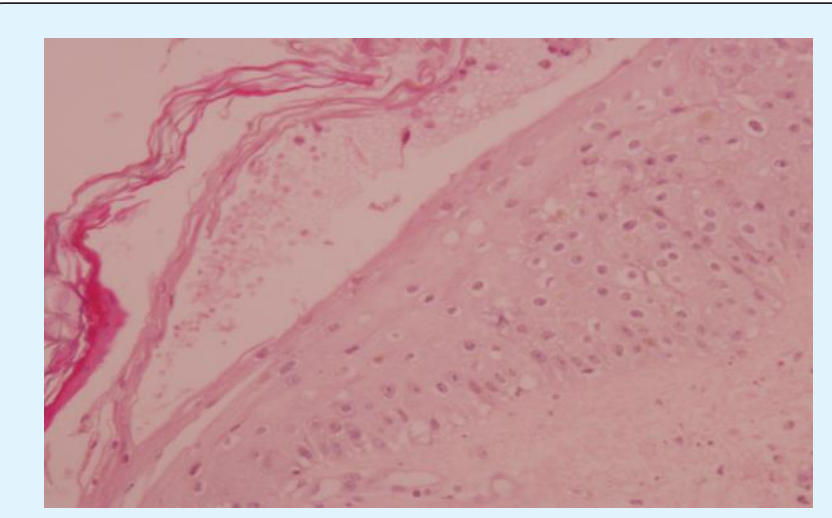

Figure 6: Histopathology of the last case of pustular psoriasis showed: the presence of parakeratosis with neutrophils plasma exudation, prominent epidermal spongiosis, clubbed widened rete ridge, edema of the papillary dermis, extravasated erythrocytes, dilated blood vessels in the papillary dermis and mild dermal inflammatory cell infiltration.

\section{Discussion}

Psoriasis may present with variable clinical manifestations, and because of this and the lack of a biological marker of disease, may be difficult to diagnose. As a result, psoriasis is still a clinical diagnosis which is defined by typical or atypical morphologic findings and appearances. The primary defect in psoriasis patients was believed to be abnormal epidermal cells proliferation, histopathologically; psoriasis is characterized by marked keratinocyte hyperproliferation, a dense inflammatory infiltrate consisting of $\mathrm{T}$ cells and neutrophils, and vascular dilatation and proliferation [13]. Abnormal cytokines production is being studied as a possible mechanism in psoriasis. However its mechanism in psoriasis pathogenesis is still unclear [14,15]. Many reports suggest that Th1 cells may mediate or maintain the disease process [16].

The present study confirmed the previously demonstrated data that Th1 cytokines and some of the pro-inflammatory cytokines are affected in the serum of 


\section{Annals of Immunology \& Immunotherapy}

patients with psoriasis. Meanwhile, we observed a significant relation between serum levels of IFN- $\gamma$ and severity of psoriasis. This suggests that the serum IFN- $\gamma$ may be used as an index for psoriasis severity and as a prognostic marker. Our results are in line with the results of Gaffen et al. On the contrary, Almakhzangy and Gaballa observed no relation between severity of disease and levels of IFN- $\gamma$ in serum of psoriatic patients $[17,18]$. This indicates that IFN- $\gamma$ has a role in psoriasis but not the principal or sole regulator of the disease.

The serum levels of IFN- $\gamma$ in our study did not correlate with gender or age of patients, this agrees with the results of Quaglino, et al [19].

In our study, the mean value of serum levels of IFN $-\gamma$ was significantly higher in patients with psoriasis in comparison with the controls; this may be suggestive evidence for its role in the pathogenesis of psoriasis. A number of previous studies also showed a significant increase in IFN- $\gamma$ in the serum of patients compared to the healthy controls. In psoriasis, the source of cytokines circulating in the blood serum is not known clearly. Very huge amounts of cytokines are needed to produce a generalized inflammation and to get a biological response at the skin $[20,21]$.

\section{Conclusion}

In psoriasis, IFN- $\gamma$ serum levels can be used as a useful estimate of the severity of the disease and may be used in daily practice as prognostic follow-up marker.

\section{References}

4. Parisi R, Symmons DP, Griffiths CE, Ashcroft DM (2013) Global epidemiology of psoriasis: a systematic review of incidence and prevalence. Journal of Investigative Dermatology 133(2): 377385.

5. Abedini R, Salehi M, Lajevardi V, Beygi S (2015) Patients with psoriasis are at a higher risk of developing nonalcoholic fatty liver disease. Clin Exp Dermatol 40: 722-727.

6. Gupta R, Debbaneh MG, Liao W (2014) Genetic epidemiology of psoriasis. Curr Dermatol Rep 3(1): 61-78.

7. Ogdie A, Gelfand JM (2015) Clinical risk factors for the development of psoriatic arthritis among patients with psoriasis: a review of available evidence. Curr Rheumatol Rep 17(10): 64.
8. Mansouri B, Kivelevitch D, Natarajan B, Joshi AA, Ryan C, et al. (2016) Comparison of coronary artery calcium scores between patients with psoriasis and type 2diabetes. JAMA Dermatol 152(11): 12441253.

9. Machado Pinto J, Diniz Mdos S, Bavoso NC (2016) Psoriasis: new comorbidities. An Bras Dermatol 91(1): 8-14.

10. Sun L, Zhang X (2014) The immunological and genetic aspects in psoriasis. Appl Inform 1: 3.

11. Lowes MA, Suarez Farinas M, Krueger JG (2014) Immunology of psoriasis. Annu Rev Immunol 32: 227-255.

12. Nograles KE, Davidovici B, Krueger JG (2010) New insights in the immunologic basis of psoriasis. Semin Cutan Med Surg 29(1): 3-9.

13. Mehta NN, Teague HL, Swindell WR, Baumer Y, Ward NL, et al. (2017) IFN- $\gamma$ and TNF- $\alpha$ synergism may provide a link between psoriasis and inflammatory atherogenesis. Scientific reports $7(1)$ : 13831.

14. Shoeib MA, El Shafey EN, Sonbol AA, Lashin SER (2015) Assessment of serum interferon $\gamma$ in psoriasis. Menoufia Medical Journal 28(2): 488-493.

15. Shankar V, Ghosh S, Ghosh K, Chaudhuri U (2011) PASI and PQOL-12 score in psoriasis: Is there any correlation?. Indian journal of dermatology 56(3): 287.

16. Verallo-Rowell VM, Katalbas SS, Evangelista MT, Dayrit JF (2018) Review Update on Topical Therapy for Psoriasis. Current Dermatology Reports 7(1): 24-36.

17. Griffiths CEM, Van de Kerkhof P, Czarnecka Operacz $M$ (2017) Psoriasis and Atopic Dermatitis. Dermatology and Therapy 7(S1): 31-41.

18. Madonna S, Scarponi C, Sestito R, Pallotta S, Cavani A, et al. (2010) The IFN- $\gamma$-Dependent Suppressor of Cytokine Signaling 1 Promoter Activity Is Positively Regulated by IFN Regulatory Factor-1 and Sp1 but Repressed by Growth Factor Independence-1b and Krüppel-Like Factor-4, and It Is Dysregulated in Psoriatic Keratinocytes. The Journal of Immunology 185(4): 2467-2481. 


\section{Annals of Immunology \& Immunotherapy}

19. Lowes MA, Russell CB, Martin DA, Towne JE, Krueger JG (2013) The IL-23/T17 pathogenic axis in psoriasis is amplified by keratinocyte responses. Trends in Immunology 34(4): 174-181.

20. Gaffen SL, Jain R, Garg AV, Cua DJ (2014) The IL-23IL-17 immune axis: from mechanisms to therapeutic testing. Nature Reviews Immunology 14(9): 585600.

21. Almakhzangy I, Gaballa A (2009) Serum level of IL17, IL-22, IFN-g in patients with psoriasis. Egypt Dermatology Online J 5: 4.

22. Quaglino P, Bergallo M, Ponti R, Barberio E, Cicchelli S, et al. (2011) Th1, Th2, Th17 and regulatory T cell pattern in psoriatic patients: modulation of cytokines and gene targets induced by etanercept treatment and correlation with clinical response. Dermatology 223(1): 57-67.

23. Diani M, Altomare G, Reali E (2016) T helper cell subsets in clinical manifestations of psoriasis. Journal of immunology research 2016: 7692024.

24. Cai Y, Fleming C, Yan J (2012) New insights of T cells in the pathogenesis of psoriasis. Cellular \& molecular immunology 9(4): 302-309. 